\title{
EFFICACY OF LOZENGES CONTAINING KEPEL FRUIT (STELECHOCARPUS BURAHOL) EXTRACT FOR CONTROLLING ORAL MALODOR
}

\author{
ABRIJANTO SOEN BING ${ }^{1}$, ABDUL MUN'IM ${ }^{2 *}$, ANTON RAHARDJO ${ }^{3}$ \\ ${ }^{1}$ Herbal Master Study Programme, Faculty of Pharmacy, Universitas Indonesia, Depok, 16424, Indonesia. ${ }^{2}$ Phytochemistry and \\ Pharmacognosy Laboratory, Faculty of Pharmacy, Universitas Indonesia, Depok, 16424, Indonesia. ${ }^{3}$ Department of Dental Public Health \\ and Preventive Dentistry, Faculty of Dentistry, Universitas Indonesia, Jakarta, 10430, Indonesia. Email: munim@farmasi.ui.ac.id \\ Received: 04 June 2018, Revised and Accepted: 05 November 2018
}

ABSTRACT

Objective: The aim of this study was to determine the effect of lozenges containing kepel fruit (Stelechocarpus burahol) in controlling oral malodor.

Methods: This study used crossover randomized control trial design. Each of the 30 research subjects received all three treatments at different times: Kepel, xylitol, and placebo lozenges. The subjects used lozenges in the morning after breakfast and afternoon after lunch. Examinations of oral malodor were performed thrice: Immediately after waking up, after breakfast, and after lunch. Measured oral odor variables included organoleptic score and $\mathrm{H}_{2} \mathrm{~S}, \mathrm{CH}_{3} \mathrm{SH}$, and $\left(\mathrm{CH}_{3}\right)_{2} \mathrm{~S}$ levels.

Results: Effect of burahol fruit extract lozenges was comparable to that of xylitol gum in reducing the $\mathrm{H}_{2} \mathrm{~S}, \mathrm{CH}_{3} \mathrm{SH}$, and $\left(\mathrm{CH}_{3}\right)_{2} \mathrm{~S}$ levels and organoleptic scores of the subjects.

Conclusion: Lozenges containing burahol fruit extract were effective in controlling oral malodor (halitosis).

Keywords: Oral malodor, Halitosis, Volatile sulfur compound, Stelechocarpus burahol, Kepel.

(C) 2018 The Authors. Published by Innovare Academic Sciences Pvt Ltd. This is an open access article under the CC BY license (http://creativecommons. org/licenses/by/4. 0/) DOI: http://dx.doi.org/10.22159/ijap.2018.v10s1.41

\section{INTRODUCTION}

Oral malodor (halitosis) is a condition in which the oral cavity has a bad odor that is evident to the affected individual and others. This is a common problem that most individuals would like to address. The causes of oral malodor include diet, oral hygiene, microbes, tobacco use, and certain medical conditions, such as pneumonia and bronchitis. The odor in the oral cavity is caused by the protein breakdown products of anaerobic Gram-negative bacteria, and these products comprise several volatile compounds, including $\mathrm{H}_{2} \mathrm{~S}, \mathrm{CH}_{3} \mathrm{SH}$, and $\left(\mathrm{CH}_{3}\right)_{2} \mathrm{~S}$ that are more commonly known as volatile sulfur compounds (VSCs). The resulting products are deposited in periodontal pockets that eventually cause oral malodor. Further, oral malodor is caused by the production and accumulation of bacteria in tonsils and pharynx.

This bad mouth odor can be overcome by the administration of a substance that can reduce VSC levels, with one such common natural ingredients being kepel (Stelechocarpus burahol [Bl.]. Kepel fruit has been empirically used by the individuals of Magelang (Central Java, Indonesia) as a traditional herb to eliminate oral malodor. In vivo tests of kepel have shown that when orally administered as a fruit powder to mice for 7 days, odorous gas content reduced (adsorbing 62.96\% $\mathrm{NH}_{3}$ and $77.78 \% \mathrm{CH}_{3} \mathrm{SH}$ ) [1]. In addition, the flavonoids contained in it can act as antioxidants with antimicrobial activity.

With the increasing growth of natural products and awareness of health and lifestyle needs of the community, there is potential for more effective forms of natural products for oral malodor. To date, the use of kepel fruit by the population as a remover of oral malodor is still traditionally consumed directly. Therefore, an improved form of a product to deliver the active ingredients in kepel fruit, such as a lozenge, would be more effective for use. The tablet form of lozenges is intended to mask the unpleasant taste and odor of active ingredients, stabilize the preparation of traditional medicine, provide an appropriate dosage, and facilitate their use.
To be used in health-care systems, traditional medicines must have scientifically reliable data. Therefore, scientific tests of the efficacy, safety, and quality standards are performed before obtaining approval for marketing of a product. The study aim was to determine the safety and efficacy of kepel fruit in controlling oral malodor by conducting a clinical trial of kepel fruit formulated as lozenges.

\section{METHODS}

\section{Study design}

This research had two phases: Laboratory research to investigate the antioxidant activity of an ethanol extract of kepel fruit using the 2,2-diphenyl-1-picrylhydrazyl (DPPH) method and subsequent in vivo research in healthy subjects to test the effectiveness of kepel lozenges using a crossover single-blind randomized controlled trial. The quantitative test of antioxidant activity involved making a DPPH solution, optimization of the maximum UV absorbance wavelength in the DPPH method, testing of the antioxidant activity of a quercetin standard solution, and testing of the antioxidant activity of an ethanol extract of kepel [2].

\section{Subjects and ethics approval}

The research in healthy subjects was conducted after obtaining approval from the Dental Research Ethics Committee, Faculty of Dentistry, Universitas Indonesia. The subjects of this study were 30 students aged 20-25 years of the Faculty of Dentistry UI who met the inclusion criteria and did not meet the exclusion criteria. The inclusion criteria were healthy men or women aged 18-25 years, intra-oral halitosis (physiological halitosis), total VSC $>2.4 \mathrm{ng} / 10 \mathrm{~mL}$ measured using OralChroma ${ }^{\mathrm{T}}$, not having dentin caries or open dental caries, and willingness to participate in the research and follow established procedures (reading, filling out, and signing informed consent form). The exclusion criteria were untreated periodontal disease ( $>1$ periodontal pocket site $>5 \mathrm{~mm}$, systemic abnormalities e.g., indigestion, respiratory problems, or diseases associated with 
Int J App Pharm, Vol 10, Special Issue 1, 2018

extraoral halitosis), menstruation or pregnancy, use of a systemic drug that suppresses saliva production, use of an antibiotic systemic medication during the study, smoking habit, alcohol habit, use of fixed orthodontic appliances, and use of dental prostheses.

\section{Study groups}

As this study used a crossover design, each of the 30 research subjects received all three treatments at different times: Kepel, xylitol, and placebo lozenges. The wash-out period of 3 days was performed between each of the three stages of testing.

Administration of lozenges was two tablets per day, which were administered at 07.00 after breakfast and at 12.00 after lunch. Measurements were performed in healthy subjects who had met the inclusion criteria and not met the exclusion criteria. Sampling and measurement were performed 3 times per day: At 04.30 immediately after waking, at 09.00 ( $2 \mathrm{~h}$ after breakfast and treatment) and at 14.00 ( $2 \mathrm{~h}$ after lunch and treatment). The treatment and measurement implementations were performed by adapting those used in the research by Fukui et al. [3].

Measurement of oral malodor variables was performed two ways: By checking the organoleptic score with the sense of smell, and measurement of VSC levels using a gas chromatograph (GC). The examination methods used were one developed by Anton Rahardjo and Takatoshi Murata and a method using the OralChroma ${ }^{\mathrm{TM}}$ GC instrument with an indium oxide semiconductor gas sensor (GC-SCS) that can measure individual VSCs; in this case, $\mathrm{H}_{2} \mathrm{~S}, \mathrm{CH}_{3} \mathrm{SH}$, and $\left(\mathrm{CH}_{3}\right)_{2} \mathrm{~S}$ were measured. The three gases are indicators of the presence of halitosis.

The measurements were performed at three time points to measure the organoleptic score using the sense of smell and VSC levels $\mathrm{CH}_{2} \mathrm{~S}, \mathrm{CH}_{3} \mathrm{SH}$, and $\left(\mathrm{CH}_{3}\right)_{2} \mathrm{~S}$ using the OralChroma ${ }^{\mathrm{TM}} \mathrm{GC}$. Hence, at every time point, four parameters were measured: The organoleptic score, $\mathrm{H}_{2} \mathrm{~S}$ level, $\mathrm{CH}_{3} \mathrm{SH}$ level, and $\left(\mathrm{CH}_{3}\right)_{2} \mathrm{~S}$ level.

Data are presented as the mean \pm standard deviation. Each data set was tested for normality using the Kolmogorov-Smirnov and Shapiro-Wilk frequency distribution tests. The paired $t$-test was performed if the data were normally distributed. Data transformation was performed if the data were not normally distributed. If the transformation results remained abnormal, the data were analyzed by performing the nonparametric test Wilcoxon test. The level of statistical significance was set to $\mathrm{p}<0.05$

\section{RESULTS AND DISCUSSION}

Table 1 shows concentration, inhibition percentage, and inhibitory concentration (IC50) of ethanol extract of kepel fruit. Testing of the antioxidant activity of the ethanol extract of kepel was performed to determine the concentration of the ethanol extract of kepel needed to reduce DPPH by 50\% (half maximal IC50). DPPH is a stable free radical that has the advantage of delocalization of the unpaired electron across the entire molecule, which means that the molecule does not undergo dimerization, as happens with other free radicals [2,4-9].

The results of antioxidant measurements using DPPH showed that the ethanol extract of the kepel fruit had a weaker inhibition level than that of the quercetin standard. However, the ethanol extract of the boiled fruit still had high antioxidant activity because it had an IC50 value $<100 \mu \mathrm{g} / \mathrm{mL}$.

Phenolic compounds or flavonoids contained in the kepel fruit have antioxidant activity that can reduce oral malodor by lowering VSC levels. The decrease in VSC levels by the polyphenol compounds contained in kepel occurs by altering the conversion of polyphenol compounds by the oxidase polyphenol enzyme into the O-quinone form, which further captures the VSC $\mathrm{CH}_{3} \mathrm{~S}$ (methyl mercaptan) that contributes to oral malodor [10]. The main components in oral malodor are VSCs;
Table 1: Concentration, inhibition percentage, and IC50 of ethanol extract of kepel fruit

\begin{tabular}{lll}
\hline Concentration $(\mu \mathrm{g} / \mathrm{mL})$ & $\begin{array}{l}\text { Inhibition } \\
\text { percentage }(\%)\end{array}$ & $\begin{array}{l}\text { IC50 } \\
(\boldsymbol{\mu g} / \mathbf{m L})\end{array}$ \\
\hline 4 & 16.9524 & 83.05 \\
8 & 19.238 & \\
12 & 21.333 & \\
20 & 26.476 & \\
24 & 28 & \\
\hline
\end{tabular}

that is, $\mathrm{H}_{2} \mathrm{~S}$ (hydrogen sulfide), $\mathrm{CH}_{3} \mathrm{SH}$ (methyl mercaptan), and $\left(\mathrm{CH}_{3}\right)_{2} \mathrm{~S}$ (dimethyl sulfide) [11].

Comparative test of lozenges containing kepel, xylitol, and placebo The advantages of a crossover design used in this study are that it minimizes individual variations, which improve the sensitivity to small differences and reduces the required number of subjects (half of the number needed in parallel design). However, the experimental time is increased, and there is the possibility of a larger subject drop out as well. In this design, the subject can be a control for him-/herself if a wash-out period is used. Compared with a parallel design, a crossover design compares different treatment effects within the same subjects, whereas the parallel design compares different treatment effects between subjects. Hence, the data variability in a crossover study is lower and the power is higher, which is shown by the more robust data with narrower confidence intervals. The main limitation of crossover design is the possibility of the presence of carryover effects, but in this study, it could be avoided by ensuring a long wash-out interval of $3 \mathrm{~d}$ between treatments.

\section{Measurement variables}

Oral malodor is a result of bacterial decomposition, in which oral bacteria work on salivary proteins to produce compound products. The process of decomposition by bacteria is said to be the main cause of halitosis formation. Anaerobic bacteria that live normally in the oral cavity are excessive, and the food particles left in the oral cavity produce odorous sulfur. The growth of Gram-negative bacteria will increase when salivary $\mathrm{pH}$ is $>7.2$. This leads to the breakdown of protein. The rough surface of the dorsum of the tongue is an ideal place for anaerobic bacteria because that area has many food particles and dead cells. The tongue coating is the main source of VSC formation in patients with periodontal disease. Therefore, removal of the tongue coating can reduce VSCs [3].

The bacterial species present on the oral surface may be either saccharolytic or asaccharolytic. Saccharolytic species use carbohydrates as a source of energy. In contrast, asaccharolytic or proteolytic species use proteins, peptides, or amino acids as the main energy source. Most Gram-positive bacteria are saccharolytic and Gram-negative bacteria are asaccharolytic or proteolytic [3].

Microorganisms, especially Gram-negative bacteria, break down protein substrates into peptide chains and sulfur-containing amino acids, such as methionine, cysteine, and cystine. Cysteine and methionine are amino acids with sulfur-containing side chains. The amino acid undergoes a chemical process (reduction) that further generates VSCs: Methyl mercaptan $\left(\mathrm{CH}_{3} \mathrm{SH}\right)$, hydrogen sulfide $\left(\mathrm{H}_{2} \mathrm{~S}\right)$, and dimethyl sulfide $\left.\left(\mathrm{CH}_{3}\right)_{2} \mathrm{~S}\right)$. There are three main amino acids that produce VSCs: Cysteine produces $\mathrm{H}_{2} \mathrm{~S}$, methionine produces $\mathrm{CH}_{3} \mathrm{SH}$, and cystine produces $\left.\left(\mathrm{CH}_{3}\right)_{2} \mathrm{~S}\right)[3]$.

In this research, oral malodor parameters that were measured were the organoleptic score and $\mathrm{H}_{2} \mathrm{~S}, \mathrm{CH}_{3} \mathrm{SH}$, and $\left(\mathrm{CH}_{3}\right)_{2} \mathrm{~S}$ levels (VSCs). The variables measured in this study were the organoleptic score. Variations in the organoleptic scores can be used as an estimation of the intensity of a person's oral malodor. The organoleptic score ranges from 0 to 5 . However, the measurement method is highly dependent 
on the researcher. It is, therefore, necessary to calibrate the scoring of trained assessors for assessment of the organoleptic score. In this study, we used five trained organoleptic assessors with a Kappa value of 0.80 and $\mathrm{p}<0.05$.

\section{Organoleptic score}

The organoleptic scores at the 04.30 time points in all groups were similar. The organoleptic scores at 09.00 and 14.00 showed differences between the treatment groups. For the measurement at 09.00, there was a decrease in the organoleptic scores in the kepel and xylitol groups, with the score being lower in the kepel group than in the xylitol group. For the measurement at 14.00, there was also a decrease in the organoleptic score in the kepel and xylitol groups, but the scores were the same. The results are shown in Table 2 and Fig. 1.

For the measurement at 04.30 , the organoleptic scores in all groups were similar. The organoleptic scores at 09.00 and 14.00 showed a difference among the groups. For the measurement at 09.00, there was a decrease in the organoleptic scores in the kepel group and xylitol group. However, the score was lower in the kepel group than in the xylitol group. For the measurement at 14.00 , there was also a decrease in the organoleptic score in the kepel group and xylitol group, but the decreases were the same (Table 2 and Fig. 1).

Statistical analysis of the measurements in the treatment group showed that at 04.30, there were no significant differences in organoleptic scores among the kepel, xylitol, and placebo groups and baseline scores. At 09.00, there were significant differences in the organoleptic scores between those of the kepel/xylitol groups and those of the placebo group and baseline scores, but there were no significant differences in the scores between the kepel group and xylitol group. The statistical analysis showed that the measurements at 14.00 were equal to the measurements at 09.00. For the measurements at 14.00, there was a significant difference in organoleptic scores between those of the kepel/ xylitol groups and those of the placebo group and baseline scores, but the differences were not significant between the kepel and xylitol groups.

\section{VSC levels}

Measurement using The Oral Chroma ${ }^{\mathrm{TM}} \mathrm{GC}$ can quantitatively measure the VSC $\left(\mathrm{H}_{2} \mathrm{~S}, \mathrm{CH}_{3} \mathrm{SH}\right.$, and $\left.\left[\mathrm{CH}_{3}\right]_{2} \mathrm{~S}\right)$ concentrations contained in oral malodor.

\section{$\mathrm{H}_{2} \mathrm{~S}$}

For the measurement at 04.30 , the $\mathrm{H}_{2} \mathrm{~S}$ concentrations in all groups were similar. For the measurement of $\mathrm{H}_{2} \mathrm{~S}$ concentrations at 09.00 and 14.00 , there were differences among the treatment groups, although the decreases were very small. For the measurement at 09.00, there was a decrease in the $\mathrm{H}_{2} \mathrm{~S}$ concentrations between those of the kepel/xylitol groups and those of the placebo group and baseline concentrations. However, the $\mathrm{H}_{2} \mathrm{~S}$ concentration of the xylitol group was slightly lower than that of the kepel group. At 14.00, there was also a decrease in the $\mathrm{H}_{2} \mathrm{~S}$ concentrations between those of the kepel/xylitol groups and those of the placebo group and baseline concentrations. In this measurement, the $\mathrm{H}_{2} \mathrm{~S}$ concentrations of the kepel group were similar to those of the xylitol group. The results are shown in Table 3 and Fig. 2.

Statistical analysis of the $\mathrm{H}_{2} \mathrm{~S}$ concentrations in the study groups showed that at $04.30,09.00$, and 14.00 , there were no significant differences between those of the kepel/xylitol groups and those of the placebo group and baseline concentrations.

\section{$\mathrm{CH}_{3} \mathrm{SH}$}

For the measurements at 04.30 and 09.00 , the $\mathrm{CH}_{3} \mathrm{SH}$ concentrations in all groups were similar. For the measurements of $\mathrm{CH}_{3} \mathrm{SH}$ at 14.00, there were differences in the $\mathrm{CH}_{3} \mathrm{SH}$ concentrations among the study groups. At 09.00, there was a decrease in the $\mathrm{CH}_{3} \mathrm{SH}$ concentrations in the kepel and xylitol groups relative to those in the baseline and placebo groups, but the decreases were very small. In this measurement, the $\mathrm{CH}_{3} \mathrm{SH}$ content of the kepel group was slightly lower than that of the xylitol group. At 14.00, there was also a decrease in the $\mathrm{CH}_{3} \mathrm{SH}$ concentrations in the kepel and xylitol groups relative to those in the baseline group and placebo group. In this measurement, the $\mathrm{CH}_{3} \mathrm{SH}$ concentration in the kepel group was similar to that of the xylitol group. However, the differences in $\mathrm{CH}_{3} \mathrm{SH}$ concentrations between those in the kepel and xylitol groups and those of the placebo group and baseline concentrations were large. The results are shown in Table 4 and Fig. 3.

Table 2: Mean organoleptic scores in the groups

\begin{tabular}{llll}
\hline \multirow{2}{*}{ Group } & \multicolumn{4}{l}{ Measurement time } \\
\cline { 2 - 4 } & $\mathbf{0 4 . 3 0}$ & $\mathbf{0 9 . 0 0}$ & $\mathbf{1 4 . 0 0}$ \\
\hline Baseline & $2.93 \pm 0.25$ & $2.07 \pm 0.25$ & $2.37 \pm 0.49$ \\
Kepel & $2.87 \pm 0.35$ & $1.17 \pm 0.37$ & $1 \pm 0$ \\
Xylitol & $2.93 \pm 0.25$ & $1.43 \pm 0.57$ & $0.97 \pm 0.18$ \\
Placebo & $2.93 \pm 0.25$ & $2.07 \pm 0.25$ & $2.36 \pm 0.49$ \\
& NS & Sig** & Sig* \\
\hline
\end{tabular}

Data are presented as the mean \pm standard deviation. Friedman test, NS: Not significant $(p>0.05)$, Sig: Significant $\left({ }^{*} p<0.01\right)\left({ }^{* *} p<0.05\right)$

Table 3: Mean $\mathrm{H}_{2} \mathrm{~S}$ (hydrogen sulfide) concentrations in the study groups

\begin{tabular}{llll}
\hline Group & \multicolumn{3}{l}{ H2S concentration $(\mathbf{n g} / \mathbf{1 0} \mathbf{~ m L})$} \\
\cline { 2 - 4 } & $\mathbf{0 4 . 3 0}$ & $\mathbf{0 9 . 0 0}$ & $\mathbf{1 4 . 0 0}$ \\
\hline Baseline & $0.0083 \pm 0.0071$ & $0.0106 \pm 0.0054$ & $0.0119 \pm 0.0040$ \\
Kepel & $0.0101 \pm 0.0068$ & $0.0088 \pm 0.0063$ & $0.0086 \pm 0.0063$ \\
Xylitol & $0.0071 \pm 0.0067$ & $0.0082 \pm 0.0064$ & $0.0090 \pm 0.0066$ \\
Placebo & $0.0083 \pm 0.0071$ & $0.0106 \pm 0.0054$ & $0.0119 \pm 0.0040$ \\
& NS & $*$ & $*$ \\
\hline
\end{tabular}

Data are presented as the mean \pm standard deviation. Friedman test, NS: Not significant $(p>0.05)$, Sig: Significant $(* p<0.01)$

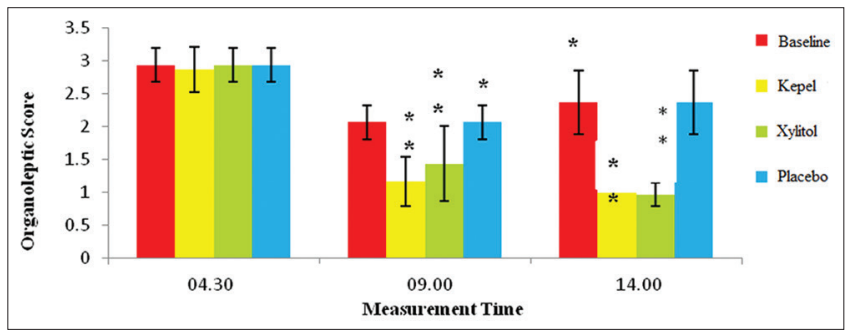

Fig. 1: Mean organoleptic scores in the study groups. Data are presented as the mean \pm standard deviation. Analysis by Wilcoxon test. $* * \mathbf{p}<0.01$ significant difference compared with baseline group. ${ }^{*} \mathrm{p}<0.05$ significant difference compared with baseline group

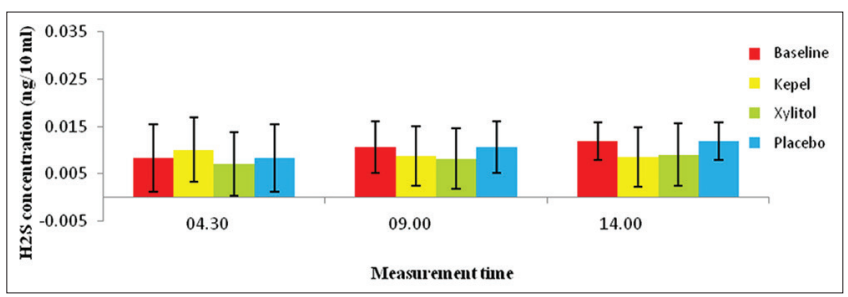

Fig. 2: $\mathrm{H}_{2} \mathrm{~S}$ concentrations in the study groups. Data are presented as the mean \pm standard deviation. Analysis by Wilcoxon test. ${ }^{* *} \mathbf{p}<0.01$ significant difference compared with baseline group. ${ }^{*} \mathbf{p}<0.05$ significant difference compared with baseline group 
Statistical analysis of the $\mathrm{CH}_{3} \mathrm{SH}$ concentrations of the study groups showed that at $04.30,9.00$, and 14.00 , there were no significant differences in the $\mathrm{CH}_{3} \mathrm{SH}$ concentrations between those of the kepel and xylitol groups and those of the placebo group and baseline concentrations

\section{$\left(\mathrm{CH}_{3}\right)_{2} \mathrm{~S}$}

For the measurement at $4.30 ; 9.00$, and 14.30 , the $\left(\mathrm{CH}_{3}\right)_{2} \mathrm{~S}$ concentration of the xylitol group were slightly different from those of the other groups. There was the difference in the $\left(\mathrm{CH}_{3}\right)_{2} \mathrm{~S}$ concentrations at 09.00 and 14.00 among the study groups. For the measurement at 09.00, there was a decrease in $\left(\mathrm{CH}_{3}\right)_{2} \mathrm{~S}$ concentrations in the kepel and xylitol groups relative to those in the placebo group and baseline concentrations. However, the $\left(\mathrm{CH}_{3}\right)_{2} \mathrm{~S}$ concentration of the xylitol group was slightly lower than that of the kepel group. For the measurement at 14.00 , there was also a decrease in $\left(\mathrm{CH}_{3}\right)_{2} \mathrm{~S}$ concentrations in the kepel and xylitol groups relative to those in the placebo group and the baseline concentrations. In this measurement, the organoleptic score of the kepel group was the same as that of the xylitol group. The results are shown in Table 5 and Fig. 4.

Statistical analysis of the $\left(\mathrm{CH}_{3}\right)_{2} \mathrm{~S}$ concentrations in the study groups showed that at $04.30,09.00$, and 04.30 , there were no significant differences in the concentrations between those of the kepel/xylitol groups and those of the placebo group and baseline concentrations.

For the measurements at $04.30,09.00$, and 14.00 , there was a decrease in the organoleptic scores relative to those in the placebo groups and baseline scores. These results are in accordance with the research of Fukui et al., showing that breakfast followed by brushing teeth can lower oral malodor. In contrast, the highest organoleptic score of oral malodor was at 04.30 . This is possible because during sleep at night until morning, a person does not eat and drink, and saliva production is minimal, so bacteria can develop in the oral cavity that eventually trigger oral malodor (Fig. 5) [3].

In the kepel group and xylitol group, there was also a decrease in organoleptic scores relative to those in placebo group and baseline scores. The decrease was greater in the kepel group and xylitol group than in the placebo group and baseline scores. These results are related

Table 4: Mean $\mathrm{CH}_{3} \mathrm{SH}$ (methyl mercaptan) concentrations in the study groups

\begin{tabular}{llll}
\hline Group & \multicolumn{4}{l}{$\mathbf{C H}_{\mathbf{3}} \mathbf{S H}(\mathbf{n g} / \mathbf{1 0} \mathbf{~} \mathrm{L})$} \\
\cline { 2 - 4 } & $\mathbf{0 4 . 3 0}$ & $\mathbf{0 9 . 0 0}$ & $\mathbf{1 4 . 0 0}$ \\
\hline Baseline & $0.0118 \pm 0.0092$ & $0.0135 \pm 0.0083$ & $0.0119 \pm 0.0040$ \\
Kepel & $0.0096 \pm 0.0094$ & $0.0117 \pm 0.0093$ & $0.0139 \pm 0.0078$ \\
Xylitol & $0.0124 \pm 0.0089$ & $0.0131 \pm 0.0083$ & $0.0144 \pm 0.0074$ \\
Placebo & $0.0118 \pm 0.0092$ & $0.0135 \pm 0.0083$ & $0.0119 \pm 0.0040$ \\
& NS & NS & $*$ \\
\hline
\end{tabular}

Data are presented as the mean \pm standard deviation. Friedman test, NS: Not significant $(\mathrm{p}>0.05)$, Sig: Significant $\left({ }^{*} \mathrm{p}<0.01\right)$

Table 5: Mean $\left(\mathrm{CH}_{3}\right)_{2} \mathrm{~S}$ (dimethyl sulfide) concentrations in the study groups

\begin{tabular}{llll}
\hline Group & \multicolumn{4}{l}{$\left(\mathbf{C H}_{3}\right)_{2}$ S Conc. $(\mathbf{n g} / \mathbf{1 0} \mathbf{~ m L})$} \\
\cline { 2 - 4 } & $\mathbf{0 4 . 3 0}$ & $\mathbf{0 9 . 0 0}$ & $\mathbf{1 4 . 0 0}$ \\
\hline Baseline & $0.0192 \pm 0.0098$ & $0.0216 \pm 0.0073$ & $0.0232 \pm 0.0044$ \\
Kepel & $0.0185 \pm 0.0099$ & $0.0176 \pm 0.0108$ & $0.0194 \pm 0.0105$ \\
Xylitol & $0.0133 \pm 0.0120$ & $0.0166 \pm 0.0123$ & $0.0192 \pm 0.0098$ \\
Placebo & $0.0192 \pm 0.0098$ & $0.0216 \pm 0.0073$ & $0.0232 \pm 0.0044$ \\
& NS & NS & NS \\
\hline
\end{tabular}

Data are presented as the mean \pm standard deviation. Friedman test, NS: Not significant $(p>0.05)$ to the presence of sugar contained in lozenges containing kepel and in gum containing xylitol. Metabolism of sugar will decrease the $\mathrm{pH}$, which, in turn, can decrease VSCs [3]. This finding showed that the use of lozenges containing kepel fruit and gum containing xylitol can reduce oral malodor. Fig. 6 shows mean concentrations of $\mathrm{H}_{2} \mathrm{~S}, \mathrm{CH}_{3} \mathrm{SH}$, and $\left(\mathrm{CH}_{3}\right)_{2} \mathrm{~S}$ in the study groups.

In the kepel group, there was a decrease in the organoleptic score and VSC concentrations relative to those in the xylitol group. This finding suggested that the use of lozenges containing kepel fruit is more potent in lowering oral malodor, which is related to the sugar content and antioxidant activity of the kepel fruit [1]. Phenolic or flavonoid compounds in the kepel fruit that work as antioxidants can reduce oral malodor by lowering VSC concentrations. The decrease in VSC concentration caused by polyphenolic compound in kepel fruit, it is caused by altering the conversion of polyphenolic compounds by the polyphenol oxidase enzyme into the 0-quinone form, which, in turn, can capture $\mathrm{CH}_{3} \mathrm{~S}$ (methyl mercaptan), which is one of the VSCs that cause oral malodor. The main components of oral malodor are the VSCs $\mathrm{H}_{2} \mathrm{~S}$ (hydrogen sulfide), $\mathrm{CH}_{3} \mathrm{SH}$ (methyl mercaptan), and $\left(\mathrm{CH}_{3}\right)_{2} \mathrm{~S}$ (dimethyl

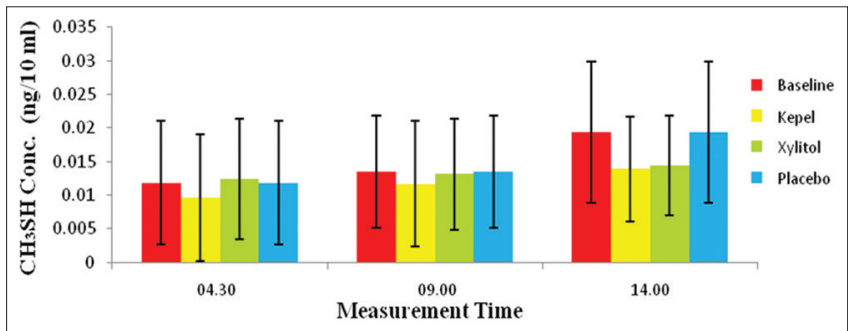

Fig. 3: $\mathrm{CH}_{3} \mathrm{SH}$ concentrations in the study groups. Data are presented as the mean \pm standard deviation. Analysis by Wilcoxon test. ${ }^{* *} \mathrm{p}<0.01$ significant differences compared with baseline group. ${ }^{*} \mathrm{p}<0.05$ significant differences compared with baseline group

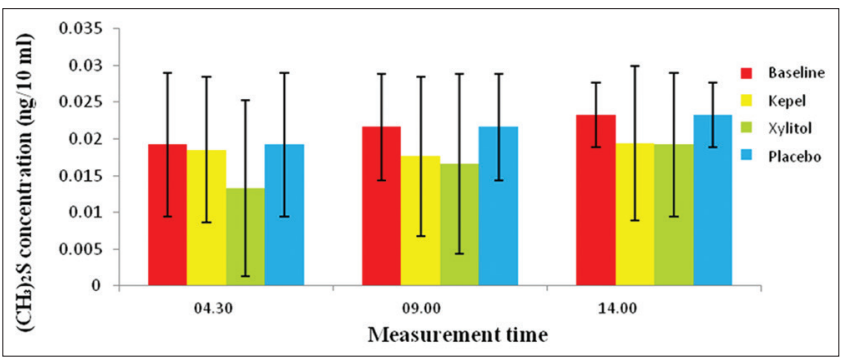

Fig. 4: $\left(\mathrm{CH}_{3}\right)_{2} \mathrm{~S}$ (dimethyl sulfide) concentrations in the study groups. Data are presented as the mean \pm standard deviation.

Analysis by Wilcoxon test. ${ }^{* *} \mathbf{p}<\mathbf{0 . 0 1}$ significant difference compared with baseline group. ${ }^{*} \mathbf{p}<0.05$ significant difference compared with baseline group

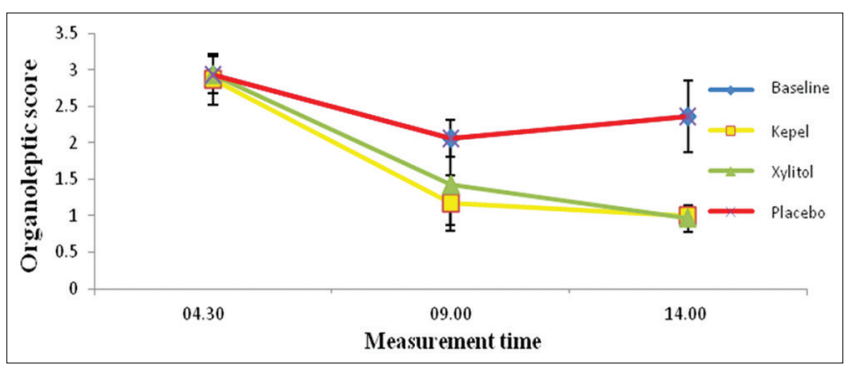

Fig. 5: Mean organoleptic scores in the study groups 


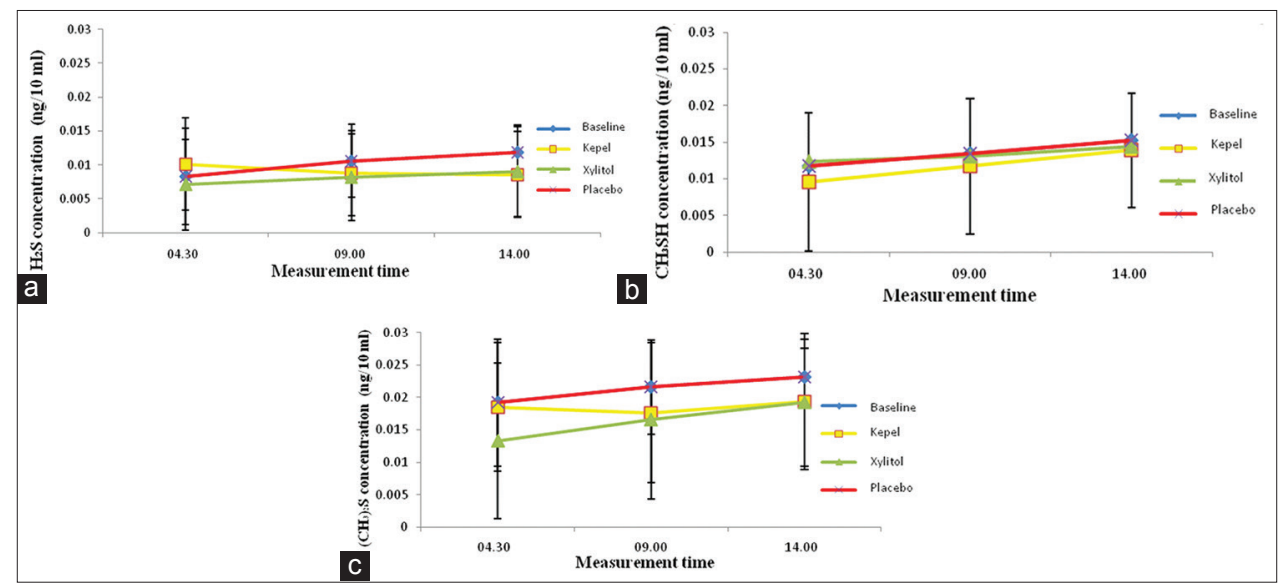

Fig. 6: (a-c) Mean concentrations of $\mathrm{H}_{2} \mathrm{~S}, \mathrm{CH}_{3} \mathrm{SH}$, and $\left(\mathrm{CH}_{3}\right)_{2} \mathrm{~S}$ in the study groups

sulfide) [11]. Some extracts from kepel fruit can reduce VSC of methyl mercaptan causing halitosis [12].

\section{CONCLUSION}

Lozenges containing burahol fruit extract (S. burahol) were found to be effective in controlling oral malodor (halitosis). Furthermore, the use of lozenges containing kepel fruit is more potent in lowering oral malodor, which is related to the sugar content and antioxidant activity of the kepel fruit. Phenolic or flavonoid compounds in the kepel fruit that work as antioxidants can reduce oral malodor by lowering VSC concentrations.

\section{CONFLICTS OF INTEREST}

None declared.

\section{REFERENCES}

1. Darusman HS. Indonesian kepel fruit (Stelechocarpus burahol) as oral deodorant. Res J Med Plant 2012;6:180-8.

2. Molyneux P. The use of the stable free radical diphenylpicrylhydrazyl (DPPH) for estimating antioxidant activity. Songklanakarin J Sci Technol 2004;26:211-9.

3. Fukui Y, Yaegaki K, Murata T, SatoT, Tanaka T, Imai T, et al. Diurnal changes in oral malodor among dental-office workers. Int Dent $\mathrm{J}$ 2008;58:159-66.

4. Ahmadi S, Marino T, Prejano M, Russo N, Toscano M. Antioxidant properties of the vam3 derivative of resveratrol. Molecules 2018;23:2446.

5. Lu JM, Lin PH, Yao Q, Chen C. Chemical and molecular mechanisms of antioxidants: Experimental approaches and model systems. J Cell Mol Med 2010;14:840-60.

6. Khanduja KL, Bhardwaj A. Stable free radical scavenging and antiperoxidative properties of resveratrol compared in vitro with some other bioflavonoids. Indian J Biochem Biophys 2003;40:416-22.

7. Devi NB, Jagetia GC. Free radical scavenging and antioxidant potential of different extracts of Colocasia gigantea (Blume) Hook. F. In vitro. Int Res J Pharm 2017;8:72-81.

8. Mantle D, Wilkins RM, Gok MA. Comparison of antioxidant activity in commercial Ginkgo biloba preparations. J Altern Complement Med 2003;9:625-9.

9. Heo SJ, Kim JP, Jung WK, Lee NH, Kang HS, Jun EM, et al. Identification of chemical structure and free radical scavenging activity of diphlorethohydroxycarmalol isolated from a brown alga, Ishige okamurae. J Microbiol Biotechnol 2008;18:676-81.

10. Negishi O, Negishi Y, Aoyagi Y, Sugahara T, Ozawa T. Mercaptancapturing properties of mushrooms. J Agric Food Chem 2001;49:5509-14.

11. Snel J, Burgering M, Smit B, Noordman W, Tangerman A, Winkel AG, et al. Volatile sulfur compounds in morning breath of human volunteers. Arch Oral Biol 2011;56:29-34.

12. Amin A, Radji M, Mun'im A, Rahardjo A, Suryadi H. Halitosis activity against volatile sulfur compound of methyl mercaptan component from burahol (Stelechocarpus burahol) fruits extract. Asian J Pharm Clin Res 2017;10:116-9 